\title{
Topical 2\% lidocaine gel versus placebo in burn wound debridement pain
}

\author{
Donna Maxwell RN, J O'Brien MD, G Sparkes MD, DH Lalonde MD \\ Burn Unit, Saint John Regional Hospital, Saint John, New Brunswick and Dalhousie \\ University, Halifax, Nova Scotia
}

D Maxwell, J O'Brien, G Sparkes, DH Lalonde. Topical 2\% lidocaine gel versus placebo in burn wound debridement pain. Can J Plast Surg 1996;4(2):109-111. This prospective, randomized, double blind study compared the effectiveness of topical $2 \%$ lidocaine gel versus placebo in the reduction of burn wound debridement pain. Each of the 19 patients in this study acted as his/her own control by having his/her burn wound debrided four times; twice with lidocaine and twice with placebo. Topical $2 \%$ lidocaine gel was found to be superior to placebo in decreasing the pain of burn wound debridement $(\mathrm{P}=0.0048$ at a $1 \%$ level of significance).

Key Words: Burn wound debridement, Lidocaine

Gel de lidocaïne topique à $2 \%$ versus placebo dans la douleur liée au débridement d'une brûlure

RÉSUMÉ : Cette étude à double insu prospective randomisée comparait l'efficacité d'un gel de lidocaïne topique à $2 \%$ versus placebo dans le soulagement de la douleur durant le débridement d'une brûlure. Chacun des 19 patients de cette étude a été son propre témoin, les plaies ayant été débridées quatre fois: deux fois avec de la lidocaïne et deux fois avec un placebo. Le gel de lidocaïne topique à $2 \%$ s'est révélé supérieur au placebo pour atténuer la douleur associée au débridement des brûlures $(\mathrm{P}=0,0048)$ à un niveau de signification de $1 \%$.

Burn wound debridement in the awake patient hurts. Parenteral analgesics or general anaesthesia are the usual solution to this problem. However, local anaesthetics may prove to be an efficacious and cost effective alternative.

Topical lidocaine has been used to decrease the pain of the burn wound itself $(1,2)$. Lignocaine has even been used intravenously to decrease burn pain (3). Lidocaineprilocaine cream has been tested against placebo in a double blind fashion for venipuncture pain in intact skin (6). Topical 2\% lidocaine gel has been found anecdotally to be useful to decrease the pain of skin abrasion (5).

We have not been able to find any reports of topical anaesthesia for the relief of burn wound debridement pain. The aim of this double blind study, in which patients were their own controls, was to see if topical $2 \%$ lidocaine gel was superior to placebo in decreasing the pain of burn wound debridement. 


\section{METHOD}

Subjects: Subjects were 19 patients admitted to a regional burn unit for treatment of a burn wound. Patients were not allowed to enter the study if they had a history of allergy to local anaesthetics; were pregnant; had severe liver disease (lidocaine is metabolized in the liver); had severe kidney disease ( $10 \%$ of lidocaine is excreted in the kidneys); had heart block or severe heart failure; were less than 16 years old; or had a decreased level of consciousness.

Study design: This was a prospective, randomized, double blind controlled study. Each patient acted as his or her own control. Each patient had the same wound debrided four times; twice with lidocaine gel and twice with placebo. The order of lidocaine/placebo delivery was randomized. Neither the nurses nor the patients knew whether identical looking tubes of gel contained xylocaine $2 \%$ or placebo (provided by Astra Pharma). After debridement, patients filled out a visual analog pain scale.

Procedure: Patients meeting the inclusion criteria had the study explained to them by one of the burn unit nurses. If they agreed to participate, they signed the consent form and were entered into the study.

Controlling pre-debridement systemic analgesia: Each patient was offered three possible alternatives before debridement: no analgesia; acetominophen $(650 \mathrm{mg})$ with codeine $(60 \mathrm{mg})$ po $1 \mathrm{~h}$ before debridement; or hydromorphone intramuscularly $30 \mathrm{mins}$ before debridement ( $1.5 \mathrm{mg}$ for 55 to $65 \mathrm{~kg}, 2.0 \mathrm{mg}$ for more than $65 \mathrm{~kg}$ ). Once a patient chose his pre-debridement systemic analgesic management for the first debridement, he was not allowed to change it for the second, third and fourth debridements.

Double blind: Each patient had the same wound debrided on four separate occasions. The pharmacy delivered a tube of gel for each debridement. Twice the tubes contained $2 \%$ lidocaine, and twice they contained placebo. The tubes of gel were identical in appearance except for an identification number. Neither the patients nor the nurses knew if a given tube had lidocaine or placebo. The pharmacy randomized the order of lidocaine/placebo delivery, and cracked the number code at the end of the study.

Technique of gel application and wound debridement: One hour before each debridement session, the wound was photographed for consistent anatomical location, and cleansed with saline. The gel with a standardized volume of lidocaine/placebo was applied to a $10 \times 10 \mathrm{~cm}$ area of the wound (standardized with a blank $10 \times 10 \mathrm{~cm} \times$-ray film). Saran wrap was placed over the gel, and the wound/gel was left occluded for $1 \mathrm{~h}$. Thirty minutes before debridement, the gel was massaged through the plastic wrap to redistribute the lidocaine in case the gel contained the drug.

Pain measurement: After each debridement, the patient completed a visual analogue pain scale. This consisted of a $10 \mathrm{~cm}$ line with the numbers 0 to 10 along the bottom. At the 0 end, the words 'no pain at all' were written. At the 10 end the words 'the worst pain 
I can imagine' were written. The nurses who performed the debridements ensured that the patients understood the pain scale and filled it out each time.

Dose of topical lidocaine: We chose a dose of $2 \%$ lidocaine that would be within safety limits even if it were totally absorbed (which it would not be). We allowed a maximum topical dose of $3 \mathrm{mg} / \mathrm{kg}$ of lidocaine. Most patients had $10 \mathrm{~mL}$ of gel $(210 \mathrm{mg}$ of lidocaine) applied.

Statistical analysis: The visual analogue pain score data were analyzed with a statistical procedure (SAS) called GLM (general linear model) for a mixed effect model. This statistical model takes into account overall mean, group effect, drug effect, group and drug interaction, patient within group effect, drug and patient within group effect and random error.

\section{RESULTS}

Topical 2\% lidocaine was found to be superior to placebo for pain relief in the debridement of burn wounds $(\mathrm{P}=0.0048)$ at a $1 \%$ level of significance. The mean pain score was 2.52 with lidocaine, and 4.14 with placebo. The total pain score (all patients) was 100 with lidocaine, and 165 with placebo.

\section{DISCUSSION}

We found that $2 \%$ topical lidocaine was superior to placebo in decreasing the pain of burn wound debridement. This is the first prospective, double blind, controlled study looking at the effectiveness of topical lidocaine in burn wound debridement pain that we have been able to find in the literature.

It is not surprising that topical lidocaine is capable of diffusing through burned skin to anaesthetize sensory nerve endings. In intact skin, EMLA ${ }^{\circledR}$ (Eutectic Mixture of Local Anaesthetics $-2.5 \%$ lidocaine $+2.5 \%$ prilocaine) cream has been shown capable of diffusing through the 'waterproof' barrier of the keratin and epidermis (6-8). Burned skin has lost the surface barrier which provides the major obstacle to drug delivery.

We chose $2 \%$ lidocaine gel because it is readily available in most hospitals for urological procedures. This means that most people who treat burn victims have easy access to it. However, it may well not be the most efficacious topical anaesthetic agent. It is possible that EMLA will be proven to be more effective because it has an extra $0.5 \%$ lidocaine and $2.5 \%$ prilocaine. This remains to be tested clinically. At the time that our study began, EMLA was not available in Canada.

We chose to apply the $2 \%$ lidocaine to the burn wound $1 \mathrm{~h}$ before debridement. We did this because the literature shows that EMLA must be applied to intact skin $1 \mathrm{~h}$ before cutting for maximal anaesthetic effect $(4,9,10)$. It is possible that either $2 \%$ lidocaine or EMLA may be effective in the reduction of pain with application times of less than $1 \mathrm{~h}$ 
because the barrier of intact skin surface is gone. This also remains to be tested clinically. Application times of less than $1 \mathrm{~h}$ would be more practical in a busy burn unit schedule.

Systemic concentrations of lidocaine have been found to continue rising up to $5 \mathrm{~h}$ after topical application (6). Seizures have been reported after topical application of $2 \%$ lidocaine gel in excessive doses in one-year-olds (1). However, if the assumption is made that all of the topically applied drug will be absorbed systemically, and the safe dose is calculated accordingly, toxic reactions to topical anaesthetics will be avoided. We chose to apply a dose of topical lidocaine which would be well tolerated if the entire dose had been absorbed systemically (maximum topical dosage $3 \mathrm{mg} / \mathrm{kg}$ ).

\section{REFERENCES}

1. Wehner D, Hamilton GC. Seizures following topical application of local anaesthetics to burn patients. Ann Emerg Med 1984;13:456-8.

2. Brofeldt T, Cornwell RN, Gunther R, et al. Topical lidocaine in treatment of partial thickness burns. Proc Am Burn Assoc 1987;110.

3. Jonsson A, Cassuto J, Hanson B. Inhibition of burn pain by intravenous lignocaine infusion. Lancet 1991;338:151-2.

4. Hallen B, Uppfeldt M. Does lidocaine-prilocaine cream permit pain free insertion of iv catheters in children? Anesthesiol 1982;57:340-2.

5. Mojares EC. Xylocaine jelly for skin abrasions. JACEP 1977;6:429-30.

6. Ohlsen L, Englesson S, Evers H. An anaesthetic lidocaine/prilocaine cream (EMLA) for epicutaneous application tested for cutting split skin grafts. Scand J Plast Reconstr

Surg 1985;19:201-9.

7. Ehrenstrom Reiz GME, Reitz SLA. EMLA - a eutectic mixture of local anaesthetics for topical anaesthesia. Acta Anaesth Scand 1982;26:596-8.

8. Lycka BAS. EMLA - A new and effective topical anaesthetic.

J Dermatol Surg Oncol 1992;18:859-62.

9. Hallen B, Olsson GL, Uppfeldt A. Pain free venipuncture. Anaesthesia 1984;39:96972.

10. Juhlin L, Evers H, Broberg F. A lidocaine-prilocaine cream for superficial skin surgery and painful lesions. Acta Dermatovenereol (Stockholm) 1980;60:544-6. 